\title{
O Trabalho Médico: Questões Acerca da Autonomia Profissional
}

\author{
Work in Medicine: Some issues Concerning Professional Autonomy
}

\author{
Lilia B. Schraiber ${ }^{1}$
} SCHRAIBER, L B. Work in Medicine: Some Questions About the Professional Autonomy. Cad.
Saúde Públ., Rio de Janeiro, 11 (1): 57-64, Jan/Mar, 1995.

The author analyzes several issues pertaining to medical practice as related to the technical autonomy characterizing professional activity in this field. She points to the coexistente of a scientific side and an empirical/pragmatic side of medicine, the latter known as the medical art. The article also discusses the complexity of medical command of technological rationality which presides over the practical use of scientific knowledge. The author defines work in medicine as a "tensive structure" and examines its consequences for self-representation by physicians, their daily work, and themselves as agents of professional labor and subjects of action.

Key words: Medicine; Work in Medicine; Self-Representations in Medicine; Medical Autonomy; Medical Technology

\section{INTRODUÇÃO}

Este texto está baseado em pesquisa que realizei no período 1986 - 1988. O tema inicial tratava das relações entre medicina e tecnologia, buscando recuperar a história da prática médica à medida que essa se desenvolveu como trabalho da sociedade. Pretendia alcançar a constituição do trabalho médico especializado e incorporador de tecnologias materiais, pois esse parecia ser um marco radical na história daquele trabalho.

De fato, significou, para a medicina, sua superação de prática de pequeno produtor privado e isolado do consultório particular, abandonando á configuração da modalidade liberal de trabalho, para reestruturar-se em um conjunto de instituições heterogêneas e de práticas desiguais: a medicina institucionalizada e empresarial, a que chamei "medicina tecnológica".

Trata-se de outra forma de intervenção, outra forma de exercício profissional e de satisfação

\footnotetext{
'Departamento de Medicina Preventiva, Faculdade de Medicina, Universidade de São Paulo. Avenida Dr. Arnaldo, 455. $2^{\circ}$ andar, São Paulo, SP, 01246-903, Brasil.
}

das necessidades da população, alterando profundamente a posição do médico na sociedade e no trabalho: seu desempenho técnico, seu estatuto social e sua ação política são refeitos, bem como são reconstruídas as bases de sua relação com os pacientes.

Analisando o significado dessas mudanças particularmente para o médico, estudei e redefini sua autonomia profissional, enquanto realidade objetiva e conceitual. De um lado, isso significou abordar o médico como sujeito coletivo e, simultaneamente, técnico, político e histórico. De outro, significou responder a algumas das mais intrigantes especificidades dessa prática, encontrando-a como trabalho de natureza muito peculiar, em nossas sociedades.

São parte dessa peculiaridade o modo como médicos, pacientes e muitos outros sujeitos da sociedade prezam a liberdade desse profissional no trabalho e buscam-na ou colaboram nessa direção ativamente; a intimidade das pessoas envolvidas nesse trabalho, cuja relação privada e exclusiva as torna sempre só duas, a ponto de se perder a visibilidade social da relação médico-paciente como uma relação também de trabalho; e, ainda, o apreço à cientificidade dessa prática, levando a rotinizações e mecanizações em 
princípio contrárias às características anteriores e fazendo com que, em situações de extrema tecnicidade, seus personagens (por qualquer dos lados que nela se insiram) "burlem", em verdadeiras estratégias de recusa, o valor científico que também lhes é caro.

Tais características, se acopladas ao empresariamento do trabalho médico em complexas articulações com ramos industriais e financeiros da produção social - o que elitizou os serviços e, ao mesmo tempo, contraditoriamente, massificou "intimidades" e "privacidades" -, terminaram por tornar muito instigante, quase imperiosa, a perspectiva de examinar a medicina "por dentro".

Foi o que busquei na ocasião, produzindo o texto intitulado Medicina Liberal e Incorporação de Tecnologia - as transformações históricas da autonomia profissional dos médicos em São Paulo (Schraiber, 1988). Hoje, decorrido um bom período de tempo, gostaria de revisitar o estudo realizado e seus dados-base em busca de uma síntese das reflexões passadas e na qual tentarei enfatizar o ângulo da auto-representação dos médicos, ainda me valendo do percurso intelectual referente à autonomia e suas questões.

Para os médicos, a autonomia profissional, constituída historicamente ao longo do século 19 e cerne da medicina liberal, veio a ser uma conquista ímpar da medicina moderna (Freidson, 1970; Starr, 1982). Sua substância é dada pela liberdade de se colocar no processo de trabalho, que foi, originalmente, ampla e global por revestir vários momentos de sua prática. Sem grandes exageros, pode-se, pois, qualificá-la como pleno exercício da subjetividade, traduzindo, da perspectiva técnica, igual posição social e político-ideológica do médico, qual seja, de autoridade exclusiva sobre a saúde e o adoecer, tanto do ponto de vista científico quanto moral.

O desenvolvimento da medicina promoveu redisposições no trabalho que implicaram constrangimento relativo à liberdade conquistada (Larson, 1980; Starr, 1982; Freidson, 1985). O ocorrido, em sua aparência primeira, mostrou-se como uma redução de tal ordem na autonomia profissional, que, para os médicos, de imediato, "neutralizava"-lhe o valor. Foi, por isso, entendido como supressão da autonomia.
Minha tese, porém, foi a de que, sob essa aparência, processou-se uma reorientação dos espaços de seu exercício, ocorrendo, de fato, transformações que mudaram as bases de apoio da realização do sujeito no processo de trabalho. A autonomia ganhou outra especificidade, e o sentido de liberdade foi requalificado, movimento que expressei como mudanças para preservação.

No caso da situação particular da medicina brasileira, esse processo não foi muito longo, ocupando um período de tempo que me permitiu estudá-lo justamente por meio das vivências de médicos partícipes das referidas transformações. Assim sendo, a metodologia que utilizei na pesquisa de campo foi o relato oral, obtendo depoimentos pessoais de médicos acerca do cotidiano de seu trabalho.

Nesses testemunhos busquei recuperar a história do desenvolvimento tecnologicamente qualificado da medicina, valendo-me de narrativas individuais bastante livres, quase em forma de histórias de vida, não fosse a ênfase dada à "vida de trabalho". Os relatos são referentes ao período 1930 - 1987, pois são fruto das entrevistas realizadas com médicos que iniciaram seu exercício profissional entre os anos 1930 e, no máximo, 1955, e que, no momento da investigação de campo (1986/87), permaneciam, apenas em parte, ainda trabalhando. No registro das experiências individuais, o que possuo, portanto, é o testemunho de uma travessia, passagem da medicina liberal para a medicina tecnológica.

Essa característica, sem dúvida, qualifica uma dada geração de profissionais, e a presente reflexão não deve ignorar esse aspecto. Desse modo, se o que esses discursos revelam não pode ser tratado enquanto pensamento médico do passado, também não será o típico hodierno. Retirando da prática médica mais atual uma parcela de suas referências, o pensamento médico que tomaremos e as representações de que se construiu são também uma transição: denotam apoios no passado e prenunciam bases do futuro, constituindo, em si, na qualidade de raiz histórica, substrato da maior importância para a compreensão das origens e gênese da atualidade. Um pensamento em transformação, cujo processo, o movimento, constituirá a principal base das considerações a seguir. 


\section{PONTOS DE PARTIDA ATUAIS}

O tema deste tópico está dado pelos já mencionados incitantes da pesquisa realizada, isto é, o que terá sido sua motivação, em razão dos aspectos instigantes da prática médica. Talvez, agora, após o seu estudo e conhecendo melhor seu movimento histórico, pudesse qualificá-los como os "contrários surpreendentes" na medicina, relacionados à natureza especialíssima desse trabalho.

O mais totalizador desses aspectos constitui sua tensão interna permanente: cristalização tensionada do trabalho médico, enquanto prática técnica e social. Ora, ser uma "estrutura instável" contrasta nitidamente, o imaginário social cunhado acerca da ação médica. Há, no interior dessa prática, uma dinâmica de polares tal que, se fosse imediatamente visível em sua forma aparente de estruturação, colocaria em cheque a segurança e mesmo a estabilidade, que costumamos associar às técnicas científicas (Freidson, 1970). É interessante notar que o autor chama a atenção para o fato de que os leigos vêem a medicina como prática segura, por sua feição de tecnologia científica. Já os médicos, mesmo sabendo das incertezas e riscos que envolvem o ato médico - em razão da natureza complexa do julgamento que nele se instala -, também terminam por assumir sua ação do mesmo modo que os leigos. $\mathrm{O}$ autor atribui esta última possibilidade exatamente à especificidade oposta da ação, qual seja, a crença dos médicos em sua própria capacidade de bem decidir, no pleno exercício de uma autonomia técnica.

A estruturação concreta da ação médica, enquanto prática construtora da socialidade da vida, é dada pelo fato de que os vários aspectos dessa prática, mesmo enquanto pólos em oposição, realizam-se efetivamente: todos juntos tecem a estrutura. Já a tensão resulta da oposição que a interação desses aspectos promove, à medida que cada um deles se realiza.

Concretizemos mais essa reflexão, discriminando esse aspecto-síntese.

A medicina, na qualidade de trabalho, é realidade técnica: transformação que o médico opera em seu objeto de intervenção (o doente), fundada em conhecimento científico (ciências naturais). Contudo, se toda técnica sugere ser aplicação das ciências, denotando repetições e roti- na por meio desse conhecimento universal que implicaria ato sempre igual, no caso da ação médica não é exatamente assim que o processo se dá. Antes, mesmo sem perder o caráter técnico-científico, todo ato médico consegue qualificar-se como ato, de certa forma, singular, único. Isso porque envolve decisão pessoal do médico na aplicação do conhecimento científico. Há, para tal envolvimento, razões não apenas da esfera da técnica, como intervenção sempre social, mas pricipalmente razões históricas (Schraiber, 1988, 1993).

Essa aplicação, portanto, não se dá de maneira direta ou imediata a partir da ciência estabelecida, senão mediante um re-ajuizamento do conhecimento científico quanto à particularidade de cada caso examinado. Pois, se a ciência é conhecimento na forma de leis gerais acerca dos fenômenos biológicos, na área da saúde, somente em sua dimensão de Saúde Pública é que as ações podem ser igualmente genéricas, realizando-se sobre coletivos, grupos de pessoas. $\mathrm{Na}$ assistência médica, o ato é sempre intervenção individualizada: incide sobre cada indivíduo, a cada vez (Freidson, 1970). É por isso considerada o exemplo mais típico de trabalho e produção social, em que a relação conhecimento $x$ técnica se revela enquanto síntese do geral no particular (Ribeiro \& Schraiber, 1994).

A prática médica, desse modo, envolve juízo subjetivo e complexas decisões de caráter pessoal. Essas características também se estabelecem em razão de seu extremo pragmatismo, pois a sociedade exige da medicina sempre uma ação, uma solução ou resposta para demandas que lhe são feitas, mesmo quando não há conhecimento científico para ampará-la (Freidson, 1970).

Nesse sentido é que podemos dizer que a ação médica envolve a formulação de conhecimento novo, representando nisso um ato de criação e de "investigação" acerca do comportamento vital em situações concretas. $\mathrm{O}$ acúmulo dessa produção, que em termos de conhecimento caracteriza a dimensão empírica da medicina, termina por conformar a chamada experiência clínica pessoal, a qual não apenas é usada como saber de referência por quem a produz, como é igualmente socializada e muitas vezes "cientificizada" (Schraiber, 1988, 1993; Dalmaso, 1991; Almeida-Filho, 1992). 
Assim sendo, creio que se pode afirmar ser o ato médico ato técnico e, simultaneamente, intelectual, então, ato simultaneamente de aplicação e descoberta de saber. Isso significará, por referência a seu caráter científico - a medicina como "ciência de curar" (tal qual é concebida pelos médicos) -, uma especificidade de ação subordinada de forma "absoluta" e "relativa" à ciência. Já por referência à sua "empiria", isto é, a medicina como arte de curar (tal qual já foi concebida), será ação de autonomia "plena" e "parcial".

Para melhor interpretar esses pólos em oposição e tentar alcançar a peculiar natureza da ação médica, seria preferível nos aproximarmos da relação ciência $x$ trabalho por mediação. Vale dizer, interpor um momento intermediário relacionado à construção do tecnológico: criação do concreto saber operatório no e do processo de trabalho, presidindo o projeto de trabalho e, portanto, o modo de organização da intervenção, operacionalidade em tese já contida no plano do conhecimento científico.

Mas essa é proposição recente no estudo das práticas em saúde (Mendes Gonçalves, 1986), cujas referências teóricas e interpretativas diferem das que suportam o próprio pensamento médico. Neste, encontraremos a busca de reduzir ao máximo, virtualmente eliminar, o empirismo da ação, figurando, pois, a noção oposta, isto é, a do trabalho "científico", em que ciência e trabalho passam a ser realidades de conexão imediata e direta, tão próximas a ponto de se "misturar".

$\mathrm{Na}$ medicina, desse modo, reveste-se de autoridade do saber científico, o saber fazer, e, ao mesmo tempo, exige-se o saber prático, instrumental, limitando a ciência e desqualificando a técnica, enquanto potencialidades distintas, mas igualmente profícuas, de conhecimento.

Um segundo constituinte da cristalização tencionada do trabalho médico que vimos examinando diz respeito à produção de serviços em atos individualizados, exclusivos e privados, tal como se apresenta sua mais tradicional unidade de produção: a consulta médica. A consulta simboliza tanto a independência do ato técnico quanto seu isolamento como produção social, aspectos reforçadores da já mencionada autonomia em sua face "plena". E, por ser concebida como componente produtivo mais importante, uma vez que remete ao ato diagnóstico, a consulta delimita hierarquias entre os vários atos técnicos existentes, sobretudo diante da intensa especialização do trabalho e hierarquização dos saberes. Esse movimento tencionará a antiga homogeneidade da técnica enquanto produção de serviços e intervenções socialmente equivalentes.

Contudo, o movimento significa, de outro lado, a construção do trabalho coletivizado em saúde. Chamo a atenção para o fato de que, no caso do trabalho médico, o uso que faço do conceito "trabalho coletivo" quer apontar sobretudo para a divisão técnica e social e suas qualificações de trabalhos interdependentes e complementares, ainda que para o trabalho médico essas características devam ser mais bem definidas. Cada atuação individualizada torna-se dependente e complementar de outras, socializando o processo de trabalho. Em certa analogia ao que ocorrera com outros ramos da produção social, também a medicina institucionaliza-se e torna-se produção empresarial, criando a necessidade efetiva de composição de atos parcelares para a satisfação das necessidades assistenciais que lhe são colocadas. O que, por razões já apontadas quanto às decisões soberanas de cada médico, tencionará a interdependência no trabalho.

Finalmente, restam dois processos a apontar. Primeiro, um "reagrupamento" ou formação de novos coletivos no interior dessa progressiva segmentação do trabalho e que é movimento diverso do anterior, ainda que igualmente produto da institucionalização da medicina. Segundo, a maciça presença de equipamentos no ato técnico.

No plano da organização social da produção dos serviços médicos, por razões financeiras e mercantis, há o estabelecimento de estratos socialmente diferenciados de clientelas institucionais. Esse processo opera a redisposição das camadas sociais, por cisões e reagrupamentos de segmentos já existentes na população. Da perspectiva do doente, isso termina por "dissolver" indivíduos exclusivos em coletividades economicamente mais homogêneas. A clientela institucional passa a ser um coletivo, processo que permite representar em "estereótipos" seus participantes e cujas características constitui muitas vezes 
fundamento de apreensão do doente individual e, portanto, uma das bases construtoras do efetivo objeto da intervenção.

O mesmo processo, visto do ângulo dos profissionais, significa divisão adicional do trabalho: da constituição do trabalhador médico coletivo, com uma dada divisão técnica e social do trabalho médico, para a redelimitação desse trabalhador coletivo em ulteriores estratificações, em termos de equipes institucionais. A divisão mais geral realiza-se em enquadramentos tecnológicos conformes com a modalidade socioeconômica da empresa. No lugar de um agente de trabalho, surgem equipes em rodízio que se relacionam com o mesmo caso, além da heterogeneidade das equipes formadas.

Finalmente, consideremos o último processo mencionado em que, no interior do ato técnico, a ação médica se reorienta em busca de objetivar progressivamente os juízos que suportam a decisão pessoal de cada médico. Esse processo, que materializa o reiterado valor da ciência para o trabalho, dá-se pela incorporação progressiva de equipamentos. Estes permitem, em formas diversas, visualizar o comportamento vital dos casos, o que opera maior transparência na decisão e na técnica, dando-lhes publicidade.

O produto de todas essas alterações será sem dúvida uma requalificação da antiga relação interindividual, privada e pessoal entre o médico e o paciente. Realizando-se enquanto, intercoletivos, mais pública e impessoal, essa nova articulação, que ainda se materializa na forma de interação entre dois indivíduos, adquiriu feições mais cientificas, mas não anulou a presença da autonomia do médico na ação.

Concluindo este tópico, diremos que, assim como a presença da autonomia na ação médica tensiona a técnica científica, o desenvolvimento científico-tecnológico tensiona a decisão autônoma, o ato independente e a produção isolada do trabalho médico. Não obstante e em contraste com a cientificização, a autonomia profissional do médico, desde a medicina liberal, segue sendo para esses profissionais a grande representação do trabalho e seu mais caro ideal de ação. Examinemos, pois, algumas de suas questões.

\section{MUDANÇAS E PRESERVAÇÃO; VELHAS E NOVAS REPRESENTAÇÕES}

Talvez o mais interessante no fato de estarmos centrando nossa reflexão nas questões da autonomia profissional resida nessa sua curiosa persistência como valor de trabalho já conjugadamente à maximização do caráter científico desse mesmo trabalho. Curiosa persistência apenas porque, enquanto a presença maior do científico se faz representar no pensamento médico como ganho positivo da história da medicina, a forma atual de exercer a autonomia mais parece perda.

A transmutação do caráter médico privado para esse mais público da técnica, que, afinal, permitirá a inscrição de outros sujeitos, já não se representa com o mesmo valor positivo que é atribuído à cientificização do ato técnico. Assim sendo, esta última parecerá aos médicos a "evolução natural" da prática, sem sequer representar uma transformação histórica, enquanto a maior publicidade da prática, que lhe é decorrente, figura, essa sim, como história: "realmente" mudança; e, como tal, tensionante dos aspectos positivos da medicina já conquistados, pondo em risco a permanência de seus sujeitos em igual posição anterior.

Essa não é só a percepção dada pela aparência dos acontecimentos, mas, em parte, o entendimento promovido por alguns estudos acerca da autonomia dos médicos, em razão sobretudo do ângulo examinado (Donnangelo, 1975; Campos, 1988; Medici, 1988). São estudos com os quais partilho certos aspectos da definição da autonomia profissional, quando a situam no âmbito das relações institucionais de trabalho e/ ou no âmbito das relações sociais de produção. Serão seus parâmetros definidores a situação autônoma de trabalho do médico, tendo por referência a posse exclusiva e pessoal dos instrumentos de trabalho ou da clientela; e sua capacidade de fixação pessoal de preços ou remuneração do trabalho, em autonomia mercantil.

Dessas noções derivam a dimensão conceitual da autonomia que se pode referir à instância de execução dos trabalhos e seu controle, seja no plano da produção dos serviços, seja no plano corporativo-profissional, em termos de representação de interesses coletivos diante das políticas governamentais de saúde. E desses ângulos há, a se considerar, efetivos cerceamentos à antiga autonomia profissional. 
Mas outros trabalhos (Donnangelo \& Pereira, 1976; Freidson, 1970), dos quais igualmente me valho, introduzem novos ângulos para exame. Trata-se da relação do médico com o saber, que define a instância intelectual do processo de trabalho e diz respeito à apropriação/controle do projeto do trabalho. Remete, no plano da produção dos serviços, à qualificação do médico de mentor do trabalho, denotando-lhe a especificidade de sujeito da ação enquanto agente da técnica. Já no plano corporativo-profissional, dirá respeito ao monopólio de saber e prática, enquanto for o médico, sujeito coletivo, o exclusivo detentor de autoridade no campo da saúde.

No plano do processo de trabalho, a relação do médico com o saber pode-se chamar de autonomia técnica, autonomia que se dá nos trabalhos individualizados - tarefas especializadas (parcelares) do trabalho médico coletivo. No plano institucional/gerencial de composição dos trabalhos, em que se faz perpassar por uma hierarquia de autoridades técnicas e institucionais, pode-se chamá-la de autonomia hierárquica (Ribeiro \& Schraiber, 1994).

Está claro que, desde o principio deste texto, centramo-nos na dimensão técnica da autonomia, com base na qual dialogamos - e há que necessariamente dialogar - com as demais. Isso porque tratamos o tecnológico sem o cindir do social e suas instâncias políticas, ideológicas e culturais. Ancorada no conceito de "re-produção" (Lefebvre, 1973), nossa reflexão buscou articular processos individualizados de trabalho à produção social, para visualizar na internalidade da técnica o plano social em que a sociedade se reproduz enquanto especificidades técnicas.

Privilegiar esse percurso metodológico derivou da intenção de captar, também articulando no ato técnico e no social, a relação médico-paciente, uma vez que, desse modo, poderíamos alcançar as realizações agente/sujeito e objeto/sujeito como constituintes do processo de trabalho. $\mathrm{O}$ estudo da intersubjetividade significa nossa aproximação da ação médica por sua dimensão de ação moral, revelando a autonomia como especificidade de uma técnica moral dependente. E, nessa instância, a autonomia se mostra como valor ético e comportamento moral.

Trata-se de comportamento cuja substância está em valorar o pessoal e o individual, que, enquanto ética, se expande para a sociedade em um projeto de vida fundado na esfera do privado, como valor.

Assim sendo, o percurso analítico eleito impôs e permitiu re-conceitualizar a noção da autonomia, evidenciando-a como o lema de uma disposição de luta técnico-política desses profissionais ao se voltarem para sua preservação. Luta em que se colocam em jogo não apenas prestígio, alta remuneração ou vantagens materiais, características que, aliadas ao monopólio corporativo de prática, permitiu a elitização desses trabalhadores, mas luta em que se sabe em jogo a própria autoridade técnico-científica, pela situação crítica a que é levada a ação médica por seus tensionamentos internos, em especial quando se refere à autonomia do agir técnico, conforme já comentado.

Pode-se compreender, então, o quanto são vitais para a profissão as questões que cercam a autonomia e quão valiosa será a busca de sua preservação, movimento que detém sentido, pois vai muito além dos requisitos vinculados às condições de trabalho ou das situações mercantis; preservar a autonomia é uma estratégia de poder; e poder de "Ordem", disciplina da vida social e projeto social de vida.

Há que lembrar que se trata de uma busca de conciliação de contrários, uma vez que se reiteram e se negam, ao mesmo tempo, condições dadas de autonomia, pois o movimento histórico tem sido o de sua afirmação em condições que lhe cerceiam igual plenitude ou iguais espaços de realização, tais como as atuais situações de trabalho, como vimos.

Contudo, também não se pode esquecer que a própria emergência da autonomia corresponde à necessidade de adequação do trabalho, como ação social, à racionalidade médica dada. Isso porque o principal suposto desta última - o da cientificidade (Luz, 1988) - desloca todo o conhecer que, no empirismo da prática, a revestiu de poder tecnológico, desqualificando como questão - na esfera da razão, porém não no âmbito da própria prática - a insuficiência das ciências naturais como única resposta para lidar com os fenômenos sociais, como o adoecer, por exemplo.

É nesse sentido com que tomamos o ato técnico, sentido no qual a técnica é subsumida ao social, que a autonomia é efetiva necessidade do trabalho. O mesmo não ocorrerá no outro sentido da noção de técnica, o que permeia exatamente o pensamento médico. Nesse outro senti- 
do, a técnica é tida como dimensão da vida liberta do social e revestida de neutralidade própria por referência a esse mesmo social - sentido que apenas encobre a subsunção contrária, isto é, do social ao técnico.

Nessas circunstâncias, no ideal de autonomia não encontraremos a legítima aspiração emancipatória de agente-técnico/sujeito-social. Mas, sob a bandeira técnica, são a soberania política e o estatuto ideológico de autoridade exclusiva, o que se quer preservar.

Examinado, porém, a prática tecnológica mais amadurecida, pode-se dizer que, para os contrários que vimos examinando, é possível vislumbrar, no plano objetivo de estruturação da ação médica, um caminho inicial de superação. Caminho ainda inadmitido, subjetivamente, até por implicar radicais mudanças de valor.

Trata-se da requalificação da ação moral que permeia o ato técnico, uma vez que, se na medicina liberal a prática se especifica como técnica moral dependente, a medicina tecnológica parece inverter tais termos. Radicalizando sua "ação de ciência", essa medicina cinde e isola a dimensão técnica da dimensão humana da prática. A diminuição da base pessoal e o aumento da base tecnológica da ação médica atual fazem a técnica moral dependente reconstruir-se em nova intervenção. Nesta, a moral é que lhe será subordinada (moral técnica dependente), transmutando seus antigos valores: do rigor moral na ação e código ético bem-estruturado para a perícia técnica e a habilidade instrumental; do dom ou vocação do homem na profissão para os equipamentos e medicamentos e seus "dons", enaltecendo a inovação tecnológica; da autoridade fundada no conhecimento científico, mas precedido pelo conhecimento humanístico, para a autoridade do saber complexo do conhecimento especializado...

A conduta moral, que repousou sobre atributos pessoais - paciência, dedicação, disponibilidade e atenção - e na qual a liberdade de sujeito encontrou como contrapartida a responsabilidade e o dever, está sendo reconstruída. Uma nova ética profissional ora emerge e vem dissociar o cuidado técnico, isto é, o tratar a doença, do cuidado humano - assistência ao doente, em seu sofrimento. E, nessas circunstâncias, a atual ação moral mostra significativa alteração das relações intersubjetivas no interi- or da prática: o outro se situa sempre na esfera impessoal da instituição. Agora, ali, se define e, ali, deve restar.

Todo esse processo de condução dos sujeitos para os espaços do tecnológico e, principalmente, a dinâmica do percurso histórico registrado vêm acentuar a cisão entre técnica e sociedade nas auto-representações.

Já vindos de uma medicina em que se alienavam do domínio consciente da socialidade de sua ação e de sua prática como um todo, não se pode, contudo, ver os médicos liberais como de todo impermeáveis ao social. Em parte, inscreviam-no em si mesmos, por aceitar "algo" de social na estreita aliança dos sentidos técnico e humanístico de sua prática. Isso lhes permitiu desenvolver peculiar senso de historicidade: no âmbito individual, a condição de sujeito reduzida à autonomia profissional, que foi mais global do que hoje, sendo técnica, hierárquica e mercantil, ao mesmo tempo; e, no âmbito coletivo, a história da medicina, vista como uma conjugação de feitos pessoais meritórios e obras individuais. Até no plano da produção social dos serviços, a organização destes lhes pareceu produto dos esforços de cada um: ser médico foi visto como podendo ser algo assim como fazer-se médico.

Não obstante, sem sombra de dúvida, ser médico era ser, enquanto tal, sujeito da sociedade. Em outros termos, à representação de prática autônoma e exercício independente da medicina conjugou-se uma imagem de sujeito técnico a que se podia aliar a figura de sujeito social, ainda que significando uma dada compreensão do ser cidadão da sociedade.

Com maior publicidade e politização da técnica, os médicos tendem a vê-la como menos "sua". Assim, o que já lhes pareceu mais livre e mais seu enquanto ato privado e apenas permeado pelo humanismo, com a incorporação da tecnologia material e a institucionalização da medicina, muda de representação. No interior desse processo, impele-se a recuperação do senso de domínio e de autonomia para um movimento reflexivo de cisão do ser sujeito. No plano das representações, o exercício da medicina não se confunde mais com o da cidadania, produzindo trabalhadores que se vêem como agentes e, em separado, sujeitos da sociedade: um "ser dividido". Ou, tal qual pode- 
mos vê-los, agentes com dificuldades cada vez maiores de traduzir tecnicamente seus juízos éticos e de perceber a ação técnica também como interação moral.

\section{RESUMO}

\section{SCHRAIBER, L. B. O Trabalho Médico:} Questões Acerca da Autonomia Profissional. Cad. Saúde Públ., Rio de Janeiro, 11 (1): 57-64, jan/mar, 1995.

$\mathrm{O}$ autor analisa algumas questões da prática médica relacionadas com a autonomia técnica que caracteriza a ação profissional. Nesse sentido aponta a existência simultânea do lado científico e do lado empírico-pragmático da medicina, mais conhecido como a arte médica; ou a complexidade de sua ação, pelas incertezas que cercam o julgamento clínico, conjugado à racionalidade tecnológica que rege $\mathrm{a}$ aplicação de suas ciências e historicamente busca ser soberana. Por tudo isto, define o trabalho em medicina como uma estrutura sob tensão, examinando a repercussão desta condição nas autorepresentaçoes dos médicos acerca da prática cotidiana, bem como acerca de si mesmos como agentes do trabalho e sujeitos da ação.

Palavras-Chave: Medicina; Trabalho em Medicina; Auto-Representação em Medicina; Autonomia Médica; Tecnologia Médica

\section{REFERÊNCIAS BIBLIOGRÁFICAS}

ALMEIDA-FILHO, N., 1992. A Clínica $e$ a Epidemiologia. Salvador: APCE/Rio de Janeiro: Abrasco.

CAMPOS, G. W. S., 1988. Os Médicos e a Política de Saúde. São Paulo: Hucitec.

DALMASO, A. S. W., 1991. Estruturação e TransFormação da Prática Médica: Estudo de Algumas das Características do Modelo de Trabalho na Segunda Metade do Século XIX e Início do Século $X X$. Tese de Mestrado, São Paulo: Faculdade de Medicina, Univer-sidade de São Paulo.

DONNANGELO, M. C. F., 1975. Medicina $e$ Sociedade. São Paulo: Pioneira.

DONNANGELO, M. C. F. \& PEREIRA, L., 1976. Saúde e Sociedade. São Paulo: Livraria Duas Cidades.

FREIDSON, E., 1970. Profession of Medicine-a Study of the Sociology of Applied Knowledge. New York: Dodd, Mead and Company Inc.

FREIDSON, E., 1985. The reorganization of the medical profession. Medical Care Review, 42: 11-35.

LARSON, M. S., 1980. Proletarianization and educated labor. Theory and Society, 9: 131-177.

LEFEBVRE, H., 1973. A Re-produção das Relações de Produção. Porto: Publicações Escorpião.

LUZ, M. T., 1988. Natural Racional Social - Razão Médica e Racionalidade Científica Moderna. Rio de Janeiro: Campus.

MÉDICI, A. C. (Org.), 1988. Planejamento I Recursos Humanos em Saúde. Rio de Janeiro: Pec/ Ensp/Abrasco. (Série Textos de Apoio)

MENDES GONÇALVES, R. B., 1986. Tecnologia e Organização Social das Práticas de Saúde: Características Tecnológicas do Processo de Trabalho na Rede Estadual de Centros de Saúde de São Paulo. Tese de Doutorado, São Paulo: Faculdade de Medicina, Universidade de São Paulo.

RIBEIRO, J. M. \& SCHRAIBER, L. B., 1994. A autonomia e o trabalho em medicina. Cadernos de Saúde Pública, 10: 190-199.

SCHRAIBER, L. B., 1988. Medicina Liberal $e$ Incorporação de Tecnologia: as Transfor-mações Históricas da Autonomia Profissional dos Médicos em São Paulo. Tese de Doutorado, São Paulo: Faculdade de Medicina, Universidade de São Paulo. 1993. O Médico e seu Trabalho. Limites da liberdade. São Paulo: Hucitec.

STARR, P., 1982. The Social Transformation of American Medicine. New York: Harper Collins Publishers-Basic Books. 